IN MEMORIAM.

\title{
Honorio Monteiro*.
}

\author{
Philomeno Joaquim da Costa
}

Catedratico de Direito Comercial na Faculdade de Direito da Universidade de Sáo Paulo.

O biólogo considera a morte até mesmo no setor espiritual como incidente imanente no principio da transformação da matéria; é um episódio como um outro qualquer no quadro de um ser vivo; o biólogo, sentindo hoje em dia adicionalmente a confusão em última análise entre a física e a química, encastela-se friamente na inexorabilidade dos ditames da lei de Lavoisier e balbucia que na natureza nada se perde e nada se cria.

O biógrafo considera porém a morte o coroamento de uma atividade do ser, notadamente no campo intelectual, e recusa enxergar aí a separação dos seus elementos para uma futura recomposição nova.

O biólogo não vê a intermitência, a interrupção ou a descontinuação e só enxerga a contigüidade da matéria. $O$ biógrafo eterniza o passageiro ou o transitório, tal como o fotógrafo apanha na sua câmara o cintilar do corisco, riscando aceleradamente o firmamento.

$\mathrm{E}$ por isto mesmo reverenciamos hoje a memória de Honorio Fernandes Monteiro, "o Honorio", como intima e carinhosamente o chamavam os seus alunos, os seus amigos e os seus colegas. A nossa homenagem é assim e também uma forma de protesto contra a sua ausência porque, como dissemos, o biógrafo, registrando sim a alta

*. Discurso proferido na sessão solene da Congregação, realizada em honra do Prof. Honório Monteiro, no trigésimo dia de seu falecimento, aos 28 de fevereiro de 1969. 
qualidade daquilo que êle analisa, rejeitará sempre o encadeiamento ciclico da matéria.

E tem razão. E a tem sobretudo agora.

Honorio Monteiro - "o Honorio" da nossa respeitosa intimidade - brilhou no zenite do nosso mundo intelectual, de modo que, iniciando o seu elogio merecido, há de comêço a nossa inconformidade sentimental com o seu afastamento. É deplorando-a que nós nos congregamos para perpetuá-lo nas nossas consciências, nos nossos espíritos e sobretudo no calor dos nossos corações.

Para nós, egoìsticamente para todos nós desta Casa, êle foi ferreiro da mesma ferraria, porque foi mestre querido dêste Convento Franciscano, forjando repetidamente tantas e tantas gerações de cultores do Direito. Particularmente ainda mais, porque, sendo nosso antecessor, foi professor de direito comercial. Os italianos, os juristas que cultuam o direito romano, Guarino, Biondi, Luzzato, Grosso, Astuti, Voci, Burdese, Maschi, Impallomeni, Albanese, de Martino, Solazzi e mesmo o heráldico de Francisci, etc., passaram de uns anos para cá a não mais se referirem diretamente ao nome do ramo jurídico no que cultuam com um amor e brilho invulgares; sempre que algum dêles deve ao mesmo fazer alusão, quasi que invariàvelmente, mas com um certo orgulho e muitíssimo carinho, diz "la nostra scienza". Então, com o mesmo orgulho e carinho idênticos, dizemos que Honorio Monteiro foi cultor da "nossa ciência", isto é e já agora do direito mercantil.

Nós, os comercialistas, temos bastante de que nos orgulharmos do que repetimos constituir "la nostra scienza". Ela representa a parte dinâmica das relações privadas entre os cidadãos; Vivante, no prefácio do seu ainda soberbo "Tratado", disse acertadamente que todos nós nascemos no âmbito do direito comercial, crescemos, vivemos e morremos na sua superfície, porque até para o nosso sepultamento se comercializa o aluguel do coche funerário. Pode não ser isto sofisticado, mas convenhamos que é real. Os franceses afiançam com razão que o belo para o sapo 
é a sapa e então não tenhamos nós, comercialistas, o acanhamento de proclamar o destaque da "nossa ciência" no campo do Direito, embora ela seja essencialmente positiva e pouco simpática ao condoreirismo das cogitações filosóficas.

Estamos convencidos de que esta declaração de amor seria de nôvo do agrado intenso de Honorio Monteiro e o é ainda da sua alma segundo os espiritualistas. De tudo e de tanto que éle foi, gostava de salientar a sua condição elevada de catedrático da sua amada, da sua querida Faculdade de Direito. Gostava da disciplina em que se especializou.

Por isto mesmo em 1929 fêz aqui concurso para a livre docência, sendo aprovado unanimemente. As duas dissertações, apresentadas segundo o regulamento de então, foram "Da mulher casada comerciante" e "Efeitos da sentença declaratória de falência sôbre o contrato de conta corrente, quanto às remessas com a cláusula - salvo embôlso".

O nosso velho Código de Comércio de 1850 , na trilha das legislações contemporâneas, admitia que a mulher casada exercesse legalmente a mercancia, sendo maior de 18 anos de idade e obtendo autorização marital prévia, que devia ser arquivada na Junta Comercial. Era um regime em que, conforme o ponto de vista do observador, já representava uma liberalização jurídica da mulher ou ainda consagrava uma tradição da sua afirmada incapacidade. Sabemos que no regime do direito romano a mulher permaneceu em posição indiscutível de inferioridade. Mas é provável que nem todos saibam que foi exatamente "la nostra scienza", ou seja o nome que atribuímos sentimentalmente ao direito mercantil, que iniciou a picada da emancipação jurídica da mulher: nas repúblicas medievais do norte atual da Itália, quando, por exemplo a "missio in possessionem rei servandae causa", ou seja a penhora de todos os bens do falido, enquanto se aguardava o acêrto dos seus débitos, abrandava os rigores infamantes 
da quebra, o comerciante deu de utilizar a espôsa como mercadora, contornando a incapacidade própria para êle comerciar; para isto lhe dava uma licença especial e expressa que, admitida a princípio nos "statuti" das corporações, transbordaram para o juiz estatal nas hipóteses de outras profissões, que à mulher conviesse exercer. Esse trabalho do professor Honorio Monteiro apresenta 112 páginas em que êle mostra que a incapacidade da espôsa já figurava em nosso direito privado mais pelo princípio da unidade da chefia do casal ser exercida pelo marido e menos pela ausência de tirocínio uxório. Analisa as conjunturas da autorização, sua extensão e sua ausência, para finalizar com o estudo demorado dos efeitos que decorriam do exercício do comércio pela mulher habilitada.

O tema, como sabemos, constitui presentemente assunto histórico. A Lei n. 4.121, de 27 de agôsto de 1962, mais conhecida como estatuto da mulher casada, instituiu, entre outras coisas, a liberdade profissional da mulher. Ela prescinde de licença do marido para exercer profissão. Fomos dos primeiros, senão os vanguardeiros, a pugnar contra uma inteligência conservadora da Junta Comercial. Esta entendia de inicio que a legislação especial, representada pelo Código de Comércio, não teria sido revogada pelo preceito genérico, abolidor indistintamente da licença prévia marital para a mulher exercer qualquer profissão. Hoje prepondera essa dispensa, o que tirou conclusivamente atualidade à tese do professor Honório Monteiro.

A sua outra dissertação mantém até hoje a mesma atualidade de quando escrita, em 1929, época em que vigorava a lei Carvalho de Mendonça de falências, de 17 de dezembro de 1908. Quando sobrevem a quebra de um dos contratantes na conta corrente, como se deve compreender o eventual estorno posterior, de quantia nela lançada em virtude do seu não recebimento efetivo?

E êste o tema abordado pelo professor Honório Monteiro em 76 páginas, girando as suas considerações objetivas em tôrno do que dispunha o art. 48 da então Lei 
n. 2.024: "As contas correntes com o falido consideram-se encerradas no dia da declaração da falência, verificando-se o saldo". A mesma coisa preceituava a lei Waldemar Ferreira n. 5.746 , de 9 de dezembro de 1929 . E o art. 45 do Decreto-Lei n. 7.661, a lei Miranda Valverde de falências, de 21 de junho de 1945 em vigência, reza: "As contas correntes com o falido consideram-se encerradas no momento da declaração da falência, verificando-se o respectivo saldo". Notamos que as regras permanecem imutáveis.

Cumpre-nos em primeiro lugar expor que o contrato de conta corrente é nada mais nada menos do que a outorga recíproca de crédito entre as duas partes, via de regra comerciantes. Embora Honório Monteiro adote no n. 7, pgs. 9/10, a definição de Carvalho de Mendonça encontrada no grande Tratado dêste último (Vol. VI, parte II, n. 982 - e pgs. 352/3 da $6 .^{a}$ e última edição de 1960), êle faz alusão feliz ao conceito dêsse contrato dado pelo grande Vivante, no seu Tratado citado atraz (Vol. IV n. 1.720, pág. 1.720 , da $5 .^{a}$ e última edição de 1929). Duas pessoas concordam em manterem entre si relações constantes de negócios, cruzando-se as entregas dos bens, valores e dinheiro, até que num determinado dia acertem normalmente as coisas. $\mathrm{E}$ intuitivo que aquêle, que mandou mais do que recebeu, seja considerado credor no final e inversamente o outro seja considerado devedor. As anotações da movimentação entre ambos se faziam num gráfico de deve e haver; sucediam-se as parcelas chamadas especificamente de remessas, umas às outras em ordem meramente cronológica; o contrato tomou o então nome do gráfico ou papel das anotações referidas. Em lugar assim de se denominar contrato de abertura recíproca de crédito, passou a ser conhecido como contrato de conta corrente, e conta corrente porque a conta gráfica continua, não pára, a conta deslisa, corre; daí a denominação de conta corrente.

É ponto de honra dos comercialistas nessa avença tipicamente mercantil, que não se pode confundir o gráfico de conta corrente com o contrato de conta corrente. O próprio 
Honório Monteiro tornou a acentuar essa particularidade em conferência judiciosa, que pronunciou no então Instituto Paulista de Contabilidade, em 2 de dezembro de 1931, cujo texto está reproduzido na Revista Paulista de Contabilidade, ns. 89 e 90 dos dois últimos mêses dêsse mesmo ano (pgs. 193/9). A confusão resulta da circunstância de que o registro das operações das remessas ou das parcelas, que formam o desenvolvimento do contrato, se faz do mesmo modo pelo qual também se registram as operações de uma conta corrente não contratual ou de um gráfico simples de conta corrente. Olhando-se um balanço de uma emprêsa, verificamos que tanto as contas correntes contratuais como as contas correntes gráficas figuram indistintamente na rubrica Contas Correntes, a despeito da profunda distinção jurídica a respeito. Foi por conhecermos êsse problema que of erecemos um trabalho, quando na presidência do aludido Instituto Paulista de Contabilidade, em 1939, ao IV Congresso Brasileiro de Contabilidade, em que propusemos que nos balanços surgisse uma nova rubrica sob o nome de Contrato de Conta Corrente. ${ }^{1}$ A distinção gráfica ficaria consagrada.

Gráfico não traduz contrato e contrato é sempre um gráfico. Isto tem uma importância muito grande na vida prática porque é sòmente nos contratos de conta corrente que ocorrem fundamentalmente alguns efeitos: a indivisibilidade da conta corrente, isto é, tudo se concentra no gráfico; outro efeito é a fluência de juros, que podem ter taxas diferentes para as entregas ou remessas entre os contratantes. E um dos efeitos do contrato de conta corrente é a chamada cláusula "salvo embôlso" em certas entregas ou remessas.

Tôdas as entregas, ou melhor, tôdas as remessas, são lançadas na conta, provocando aritmèticamente uma alteração no saldo em potencial. Ocorre que nelas existem valores que se inscrevem na grande categoria dos créditos, que podem ser pagos pelos devedores respectivos, mas que

1. Do Contrato de Conta Corrente na Contabilidade. 
também podem não ser pagos. É o caso padrão do endôsso por um ao outro contratante de um título de crédito contra terceiro. Realizada a transferência, realizada na linguagem especifica do contrato de conta corrente a remessa, o remetente se credita pelo valor do título, que endossou, e o recipiente se debita como endossatario-beneficiário. Resgatado o papel pelo responsável, nada mais há a se considerar, mas se acontece o contrário, não ocorrendo o resgate, entende-se que o lançamento de transferência do título representou um pagamento "pro solvendo". A falta do resgate determina o estôrno. É em virtude disto que se afirma que as entregas ou as remessas de títulos de crédito, por um contratante ao outro, se efetuam com a cláusula salvo embôlso; estornam-se, se não houver o efetivo pagamento dos seus valores pelos responsáveis respectivos, circunstância que a gente entende ser natural.

Acontece porém que na falência há o princípio vital da "par conditio creditorum": todos os credores são rigorosamente tratados dentro da sua classe. A quebra provoca naturalmente o encerramento da conta corrente contratual, apurando-se o saldo. Este deveria ser em princípio imutável, mas observa acertadamente Honório Monteiro (pgs. 43/4) "poderia parecer que o saldo, a que se refere a nossa lei, seja o resultante do balanceamento da soma da coluna deve e haver do gráfico, mantidas intactas as parcelas aí lançadas. Tal não é verdade entretanto. O saldo, que a lei diz dever ser verificado, é o saldo verdadeiro, real, e não o saldo materialmente manifestado pelo quadro, pois êste... não tem a fôrça de alterar a natureza das parcelas nêle lançadas, nem de tornar verdade os erros porventura aí cometidos". Aplicando-se o princípio da efetivação da condição resolutiva, concilia-se a inadmissibilidade de modificação do saldo da conta corrente, pela da falência de qualquer das partes com a realidade de parcelas que representaram nada. Existe uma série grande de problemas práticos em tôrno do assunto, que Honório Monteiro resolve bem, como, por exemplo, o caso em que o endossatário do 
título de crédito, ou recipiente do seu valor no contrato de conta corrente, o descontou e o pagou no seu vencimento; há a hipótese em que o endossatário ou recipiente fêz o estôrno do título e quer exercer o direito de retenção, apesar de aumentado o seu saldo credor ou de diminuido o seu saldo devedor. A matéria tem vivência diuturna nas aberturas bancárias de crédito em conta corrente.

Honório Monteiro, com o falecimento em 12 de novembro de 1931, do pranteado professor Octavio Mendes, passou a reger a cátedra. Em maio de 1932, tendo o grande Waldemar Ferreira assumido a Secretaria da Justiça na interventoria de Pedro de Toledo, resultando, depois da epopéia de 9 de julho do Movimento Constitucionalista, o seu exílio, Honório Monteiro ficou na regência das duas cadeiras de direito comercial. Em 1933 ensinou ainda a mesma disciplina no então curso de doutorado, hoje de especialização. Os bachareis dêsse ano o elegeram paraninfo da turma, quebrando a tradição da escolha de catedrático.

Inscreveu-se no decorrer do ano para o concurso à vaga com a morte de Octávio Mendes. Aprovado em segundo lugar, tendo o primeiro cabido a Ernesto Leme, Honório Monteiro ofereceu o melhor trabalho de direito de todos quantos produziu. A sua tese entitulava-se "Do crédito bancário confirmado", com 171 páginas de texto e com quasi 70 páginas de anexos.

"La nostra scienza" revela que, no incremento do comércio transatlântico de cereais e produtos agrícolas, em geral na direção da América para a Europa, quando a navegação a vapor se intensificou por volta dos meados do século passado, as flutuações favoráveis ao comprador no mercado da oferta e da procura germinaram a interessantíssima cláusula cif, que por sinal foi a tese apresentada pelo mestre Ernesto Leme no mesmo concurso. A sigla cif, como sabemos, simboliza as iniciais das palavras inglesas "cost", "insurance" e "freight" (custo, seguro e frete). Os importadores europeus da época não podiam 
manter sempre representantes nas plagas distantes da América, que se encarregassem da compra dos produtos agrícolas e do seu despacho maritimo, cobrindo-as com o seguro. Com as condições favoráveis do mercado, conseguiram impôr aos vendedores que êstes se encarregassem de obter praça nos navios, despachando as mercadorias vendidas, providenciando ao mesmo tempo o seu seguro no transporte marítimo. Surgiu daí a cotação dos produtos pelos exportadores, em que o preço incluía o seu seguro e o seu frete marítimos. E o chamado preço-cif.

A lei da oferta e da procura, tendo-se em vista a ópera de Verdi, ao se referir à mulher, "è mobile qual piuma al vento, muta d'accento e di pensiero". O mercado flutuou em favor dos vendedores, com a escassez das mercadorias; êles passaram a exigir inversamente o pagamento antecipado do preço das suas vendas.

Podemos compreender fàcilmente os inconvenientes dos sistemas de pagamentos das exportações, depois da chegada ou antes da partida das mercadorias. $O$ vendedor corria no primeiro caso os riscos da solvabilidade do comprador distante e êste, por seu turno, na segunda hipótese, enfrentava os riscos do recebimento de mercadorias viciadas ou diferentes, sem se contar com a imobilização de quantias grandes durante o período do transporte.

Adotou-se o expediente da intervenção de um banco para assegurar tanto o exportador como o importador. Honório Monteiro sintetiza o nôvo mecanismo negocial (n. 9 pgs. 15 no fim): "Comprador e vendedor, sem qualquer interferência de terceiro, contratam a compra e venda de certa partida de mercadoria. Por melhor se garantirem contra percalços da transação, obriga-se o comprador a conseguir de um banco, não só a abertura de crédito de importância igual ao preço a pagar, mas, ainda, que êsse crédito seja confirmado pelo banco ao vendedor, com a declaração de ser em benefício dêste e irrevogável. $O$ vendedor assume a obrigação de transferir ao banco os documentos representativos da mercadoria expedida, no mo- 
mento de utilizar-se do crédito". É êste assim o utilissimo instituto jurídico do crédito bancário confirmado. A sua prática tornou-se tão importante, que os Congressos das Câmaras Internacionais de Comércio resolveram uniformizá-la periòdicamente, editando em 1933 as Regras de Viena, revendo-as em 1951 como Regras de Lisboa e em 1963 como Regras do México².

Honório Monteiro faz uma análise da noção técnica do contrato, sua natureza juridica, sua realização e cuida por fim dos direitos e obrigações das partes contratantes. Realiza êsse trabalho escudado na mais autorizada doutrina, fazendo jus a que afirmemos representar a sua dissertação a melhor monografia entre nós sôbre a matéria do mais alto valor prático.

Em 1934 se criou acertadamente mais uma cadeira de direito comercial e para ela foi aproveitado Honório Monteiro, nomeado destarte catedrático no dia 3 de junho. No mesmo ano passou a fazer parte do Conselho Técnico Administrativo da Faculdade.

Em 1943 êle foi nomeado diretor da nossa Faculdade e releva notar que o foi exatamente num período de reação franca dos estudantes desta Casa às restrições do chamado Estado Nôvo, com as franquias constitucionais restringidas como agora se repete infelizmente. Quem quer, que pretenda ser politicamente equilibrado, não pode amarrar-se a tabus juridicos e deixar que a baderna se aposse impunemente das instituições. Mas quem é simultaneamente professor nesta Casa de tanta espiritualidade e, sobretudo, de tanto amor ao Brasil, não pode deixar de se entristecer, ao sentir que a fôrça bruta militar supera, presentemente. a fôrça eterna dos primados jurídicos. Praza aos céus que a eclipse seja a mais breve possível e não se transforme na durabilidade das noites hibernais nos polos... Procurou

2. LAURo MUNIz BarReto precedeu de comentários substanciosos os textos em português confrontados das Regras de Viena e de Lisboa, na Revista de Direito Mercantil, 1953, pgs. 17 até 56. 
Honório Monteiro dedicar-se à manutenção da vitalidade da nossa querida Faculdade enquanto seu diretor.

Modificado o regime policial do nosso Govêrno central. em 1945, o então nosso diretor não fugiu à colaboração política; interrompeu as suas atividades docentes para se eleger deputado à Assembléia Constituinte em 1946. Viria a confessar nesta o seguinte: "Presto, senhores, no momento, meu testemunho pelo desapontamento que no primeiro instante sofri. Já no último quartel da vida, afeito apenas aos livros, ao meu escritório de advocacia e à serenidade da cátedra, confesso-lhes meu choque ao perceber, ao sentir o trepidar das paixões e o entrechoque das correntes políticas".

Honório Monteiro foi integrante da Grande Comissão da Constituição, que esboçou a nossa Lei Magna democrática, de 18 de setembro de 1946. A sua colaboração foi destacada, como podemos todos nós compreender e admitir. $\mathrm{E}$ é muito importante assinalar agora que êle, transformada a Assembléia Constituinte em parlamento ordinário nacional, foi eleito para a presidência da sua Câmara dos Deputados, em cujo pôsto honroso ficou até 19 de marco de 1947. Declarou, ao assumir a direção da Casa baixa do nosso Parlamento: "Venho das venerandas arcadas do Convento de São Francisco — da gloriosa Faculdade de Direito de São Paulo - cujas tradições liberais e democráticas não desmentirei jamais, como não trairei nunca a confiança em mim depositada. Podeis estar seguros de que, no fragor da luta pelo império do Direito e reinado da liberdade, não ouvirei nunca sussurros de interesses pessoais, tentações de egoismos ou reclamos extremados".

Em 20 de outubro de 1948 era Honório Monteiro nomeado para o alto pôsto de Ministro do Trabalho do Presidente Gaspar Dutra. Esta pasta grangeara uma fama triste de ninho de politiqueiros, indiferentes aos interesses reais do País ou pouco sensíveis a uma evolução imanente da melhoria indispensável da classe operária. Honório Monteiro evitou a demagogia e desempenhou as suas novas 
atribuições árduas, com um profundo convencimento de espírito trabalhista. Elaborou o Decreto n. 27.048, de 12 de agosto de 1949, que regulamentou a Lei $n$. 605, de 5 de janeiro de 1949, relativa ao repouso semanal remunerado e ao pagamento de salário nos dias feriados. São de sua iniciativa as instruções reguladoras da higiene e seg'1rança do trabalho nas minas, a criação da categoria econômica dos guardadores de automóveis como trabalhadores autônomos, no quadro de atividades da Consolidação das Leis do Trabalho, a fixação de salário-base para associados e diversos sindicatos, a instalação da carteira de acidentes no trabalho do então I.A.P.C., as instruções sôbre o valor do salário-base dos trabalhadores avulsos segurados do então I.A.P.T.C., o regulamento para as eleições sindicais, que há mais de um decênio não se realizavam. Permaneceu como Ministro do Trabalho até 29 de junho de 1950 , tendo cumulado interinamente, durante cêrca de seis meses, a pasta da Justiça.

Não se reelegendo em 1951, retornou para o exercício da sua cátedra de direito comercial, a cuja frente ficou até o dia 25 de junho de 1964, quando completou a idade provecta de setenta anos, pois Araraquara o viu orgulhosamente nascer no mesmo dia de 1894. E foi êle, depois de ter colaborado valiosamente nos mais altos postos do Govêrno da República, representante desta douta Congregação no Conselho Universitário, até quando se aposentou compulsòriamente em obediência a ditame de ordem constitucional. Também, criado o Conselho Estadual de Educação, foi nomeado, com mandato por seis anos para compô-lo, elegendo-se de pronto presidente da sua Câmara de Ensino Superior, postos em que por último serviu com a mesma dedicação, com o mesmo ardor, com a mesma perseverança e com a mesma correção que marcou a linha reta da sua vida tão proveitosa.

A sua obstinação, a sua perseverança, o seu ardor não se escondiam exatamente quando advogava. Somos testemunhas disso. Chegava à indisposição com os seus colegas quando não via aceitos os seus desejos ou os seus argu- 
mentos. Pelejava espanholamente, isto é, botava $101 \%$ da sua alma na meta a que se propunha.

Este é o debuxo de Honório Fernandes Monteiro, que coroou a sua ligação eterna com esta Casa do Direito com o recebimento, depois de jubilado, do título de professor emérito.

Sucedem-se os Mestres de Direito uns aos outros na Perenidade aqui da docência jurídica. Inscrevem indelèvelmente os traços das personalidades respectivas. Vemos tantos riscos fulgurantes na história da nossa muito amada Faculdade do Largo de São Francisco, viveiro de juristas, forja de juízes, alambique de estadistas. Quando nesta solenidade de preito sincero à memória de mais um batalhador, que descança, quando, registramos a personalidade marcante de Honório Monteiro - deixem-nos repetir carinhosa e cordialmente, quando reverenciamos o Honório, o nosso Honório - quando enfim fixamos as virtudes múltiplas dêsse nosso antecessor, colocâmo-lo no panteão da nossa consagração intensa.

A excelentíssima viuva, dona Zuleika Toledo Monteiro, companheira de todos os maus e bons momentos do seu Honório, do nosso Honório, a quem deu a estupenda prole de onze filhos e também a êstes manifestamos o nosso respeito e a nossa dor. Com a sinceridade da nossa homenagem cordial e profunda à sua memória existe um pouco de lenitivo por êste repouso obrigatório do companheiro inesquecível.

Afirmamos que o biólogo vê na morte um episódio da transformação da matéria. Ao contrário, o biógrafo vislumbra aí a consagração. Pelo muito que Honório foi, pelo seu companheirismo caloroso à nossa grei de sacerdotes do Direito, reunimo-nos aqui em sessão solene. E contritos, genuflexos, pesarosos, inconformados, mortificados, proclamamos as suas virtudes para ecoarem de hoje para sempre.

Honório Monteiro continuará no calor dos nossos corações e viverá eternamente nos corredores desta nossa querida Academia, da sua adorada Faculdade! 